\title{
Architettura e Matematica: Metodi analitici, metodi geometrici e rappresentazione in architettura Orietta Pedemonte
}

The conference "Matematica e Architettura: metodi analitici, metodi geometrici e rappresentazione in architettura" (Mathematics and Architecture: analytic methods, geometric methods and representation in architecture) took place 13-15 January 2000 at the S. Verdiana campus of the Faculty of Architecture of the University of Florence. The conference was jointly organized by the Architecture and Design section of the Department of Progettazione dell'Architettura and the Department of Mathematics and Applications for Architecture.

This conference was part of a series of meetings between mathematicians and architects that began in 1997, following the inauguration of a new curriculum of the course of study for an degree in architecture. The first "Mathematics and Architecture" conference, sponsored by the Mathematics Institute of the Facolty of Architecture at the University of Florence was held in May 1997; the proceedings were eited by Orazio Arena and published by Alinea of Florence. The goal of the meeting was essentially didactic: what kind of mathematics should be taught in a faculty of architecture? This is not a new problem, and it is complicated by the diversified panorama of disciplines (including urban design) that are taken into consideration by Italian faculties of architecture. Naturally, among the various topics discussed was the current research among mathematicians, architects and urban designers.

The second conference of the series was held in Ferrara in May 1998, organized by F. Segala and C. Alessandri of the Faculty of Architecture of the University of Ferrara. This conference maintained the emphasis on didactics that characterized the first. The third conference, sponsored by the Department of Construction and Mathematical Methods in Architecture of the Second University of Naples, was held in Naples in June 1999. While maintaining a component relating to didactics, this conference also featured presentations of research in progress concerning architecture and urban design related to applications of mathematical methods and instruments. The proceedings, edited by Luciano Basile and Livia D'Appuzzo are to be published by the Istituto di Studi filosofici di Napoli.

The January 2000 conference was of a slightly different nature, due to its joint sponsorship by mathematicians and architects. Its object was to present studies and research that make evident the relationships between methods that are analytic, geometric and representatiove of the science of architecture. The proceedings, edited by Orazio Arena and Marco Bini, will be published by Alinea of Florence.

The theme of the first day of the 2000 conference was "Geometry and Architecture". Mario Docci, dean of the Faculty of Architecture of the University "La Sapienza" of Rome, presented the research in progress on the Colosseum of Rome, describing both the methods used in the survey of the monument and the unresolved problems relating to the construction itself. The debate about the form centers on the definition of the perimeter: is it an oval or an ellipse? The object of the survey conducted by the team led by Dr. Docci is to resolve the debate, which concerns not only the physical construction of the Colosseum, but also the methods used in its geometrical layout, rendered exceedingly difficult by the monumental scale of the 
building. The second presentation, by Maria Teresa Bartoli of the University of Florence, continued the theme of amphitheatres, hypothesizing as to various schemes and taking as a point of departure a drawing by Villard di Honnecourt. She also presented a numeric hypothesis, showing how this theory compared to actual amphitheatres, such as the Colosseum. Orietta Pedemonte, University of Genoa, presented the use of various rythmical, geometrical schemes as a basis for architectural designs, from the Sacred Cut to fractals. Later in the morning Stefano Bertocci of the University of Florence presented, unfortunately only briefly, a study of the architecture of Petra, discussing the changes in form and techniques with the passing of the centuries. Bertocci is also attempting to define the proportionl module or grid. used in the rock architecture of Petra by analyzing the facades of the remaining structures. A presentations by Franca Manenti Valli, University of Reggio Emilia, related to "meter" in architecture, both in graphic representations and in its function as a cognitive instrument and, as such, a scientific tool to be used during the restoration process. Domenico Taddei, University of Florence, examined the antique cassero of Fulignano and its relationship to the golden section. Carmela Crescenzi, University of Florence, proprosed a geometric genesis, representation and mathematical definitions for Islamic domed structures and for the "umbrella vaults" of Brunelleschi and Borromini.

The second day of the conference began with the inauguration of an exhibit of drawings, projects and works by the Florentine architect L. Vagnetti at the Accademia del Disegno in Piazza S. Marco. The day continued with an afternoon dedicated to the theme of "Analytic Methods Applied to Architecture and Construction". Paolo Manselli, University of Florence, spoke about the regola (rule) set forth by Antonio da Sangallo the Younger in a drawing belonging to the Uffizi Gallery (Uffizi no. 267A), according to which the cupola of the Basilica of St. Peter at the Vatican was to have been executed (the project was never realized, but for which there exists a large-scale wooden model). Prof. Manselli is attempts to establish whether or not the profile of the cupola shown in the drawing was actually drawn using the rule set out therein. Marcello Scalzo, University of Florence, spoke about Giuliano San Gallo the Elder's drawings and their metric interpretation. There followed presentations of a more technical nature dealing with present-day problems. The presentation by Anna di Falco and Massimiliano Lucchesi on the stability of columns represented in the important field of problems related to the the verification of the safety of building elements exposed to compressive force. The presentation of Silvia Briccoli Bati, University of Florence, also dealt with methods and applications of statics. On the other hand, the presentations by Aldo Ventre (Second University of Naples), Luciano Basile and Antonella Violano (both of the University of Naples "Federico II"), brought to light an aspect that is less well-known but of great relevance. They presented the application of a matrix of criteria in order to evaluate priorities during the very early planning phases of a project. The case that they discussed concerned choosing the optimal location of a water purifying plant, but the method would be valid for the first phases of any architectural project. Antonio Matura and Serena Sanseviero (University of Pescara) proposed a statistic-mathematic model as a basis for choosing an urban planning scheme.

The theme of the conference's last day was "Proportionality and Modularity". The first presentation, by Emma Mandelli, University of Florence, was about surveys of S. Miniato al 
Monte, Florence, and the geometric studies successively based on them. Giancarlo Cataldi presented his work on Roman urban and exurban territorial planning. He discussed how the Romans, both theoretical and practical, laid out the entire Italian peninsula using a square grid, the dimensions of the largest module of which were based upon the distance that could be covered in day's march by the army. Traces of this planning module are still clearly visible today, both in the street layouts of modern cities and in the division of fields in the country. Marco Bini presented his analysis of the architecture of chapels belonging to Florentine nobility, making evident how the proportions used in the designs form a matrix that results in the concatenation of forms and an extraordinary architectural harmony. Again relating to the identification of proportions and geometry, Cecilia Luschi, University of Florence, examined the Castello di Prato and compared it to the more famous castles of Federico II, Maniace and Castel del Monte. Roberto Corrazzi, University of Florence, spoke of geometric studies undertaken with Barbara Aterini and Amedio Giusti on S. Maria del Fiore. The presentation that was the most mathematic, that of Anna Maria Pagliuca of the University of Florence, was about topics related to the logorithmic spiral and the Fibonacci numbers. Michela Rossi, University of Florence, spoke about the relationships between natural, geometric and artistic forms. Giuseppe Conti of the University of Florence made evident the relationships between mathematics, music and architecture, citing the numerous mathematicians of the past who have occupied themselves with music theory, and of the famous architects of the Renaissance who applied musical proportions to their designs.

First published in the NNJ online April 2000

\section{The reporter}

Orietta Pedemonte, Associate Professor, teaches mathematics in the Faculty of Architecture of the University of Genoa and at the Scuola di Specializzazione in Restauro dei Monumenti (School for Specialization in Restoration of Monuments). Her past research interests were tied to functional analysis, while presently her research concerns two themes: the relationships between mathematics, art and architecture in their historical development; mathematical methods in urban design and geographical information systems. She is also in didactic and educational research. She is a member of the Italian Commission of UNESCO. 